\title{
Evaluation of virtual fixed points in the response spectrum analysis of a pile-supported wharf
}

\author{
J.-W. YUN*, J.-T. HAN† and S.-R. KIM†
}

\begin{abstract}
Response spectrum analysis is widely employed in the seismic design of pile-supported wharves, as it can easily determine the maximum response of a structure. The analysis typically uses virtual fixed points to model the structure, without modelling the ground, as the structure is assumed to be a frame. Virtual fixed points can adequately simulate pile responses under horizontal static loads; however, pile responses under seismic loads have not been well studied. Therefore, the dynamic centrifuge tests evaluate the applicability of response spectrum analysis, using virtual fixed points, to the seismic design of a pile-supported wharf. Comparison of results from scale models $(3 \times 3$ groups of piles from sections of Pohang New Port, Korea) with those from the analysis showed that the response spectrum analysis using virtual fixed points does not adequately simulate the natural period or pile bending moment of a pile-supported wharf system.
\end{abstract}

KEYWORDS: centrifuge modelling; earthquakes; standards \& codes of practice

Published with permission by the ICE under the CC-BY 4.0 license. (http://creativecommons.org/licenses/by/4.0/)

NOTATION

$D$ pile diameter

EI bending stiffness of the pile

$E_{\mathrm{m}} \quad$ elastic modulus of the model pile

$E_{\mathrm{p}} \quad$ elastic modulus of the prototype pile

$I_{\mathrm{m}}$ moment of inertia of the model pile

$I_{\mathrm{p}}$ moment of inertia of the prototype pile

$K_{\mathrm{h}} \quad$ coefficient of horizontal subgrade reaction

$N$ average $N$-value of the ground, from its surface to $1 / \beta$, as determined by standard penetration testing

$n \quad$ scale factor applied to the experiment

\section{INTRODUCTION}

Elastic analysis using response spectra can calculate the maximum response of a structure based on the significant modes of its response spectrum curve (Kiureghian, 1981; Kiureghian \& Neuenhofer, 1992; CEN, 2005). This approach is simple and therefore widely used in evaluating the performance of bridges and other structures. It also can combine multiple modes (CEN, 2005; Su et al., 2006; Taghavi \& Miranda, 2010), most typically by a complete quadratic combination (Wilson et al., 1981; Jiahao, 1992; Su et al., 2006).

The response spectrum analysis of a pile-supported wharf generally models each pile with a virtual fixed point or by using a spring method and does not model the ground (PIANC, 2001; PARI, 2009). Using virtual fixed points is similar to the equivalent cantilever model used to

Manuscript received 25 January 2019; first decision 23 April 2019; accepted 4 June 2019.

Published online at www.geotechniqueletters.com on 16 September 2019.

*School of Geo-Space Engineering, University of Science and Technology, Daejeon, Korea.

$\dagger$ Department of Infrastructure Safety Research, Korea Institute of Civil Engineering and Building Technology, Gyeonggi, Korea. tDepartment of Civil and Environmental Engineering, Seoul National University, Gwanak-gu, Seoul, South Korea. approximate the static lateral pile-head response of an actual soil-pile system (Nair et al., 1969; Chen, 1997; Chiou \& Chen, 2007). This method uses a line corresponding to one half of the inclined angle of the ground surface as a virtual ground surface. It is assumed that the virtual fixed point is located at a distance $1 / \beta$ below the virtual ground surface (PIANC, 2001; PARI, 2009), where $\beta$ is calculated as follows

$$
\begin{aligned}
& \beta=\sqrt[4]{\frac{K_{\mathrm{h} D}}{4 \mathrm{EI}}}\left(\mathrm{cm}^{-1}\right), \\
& K_{\mathrm{h}}=0 \cdot 15 N_{\text {ave }}\left(\mathrm{N} / \mathrm{cm}^{3}\right)
\end{aligned}
$$

Virtual fixed points are widely used and can adequately simulate pile responses under horizontal static loads; however, little attention has been paid to pile responses under seismic loads (Nair et al., 1969; Chen, 1997; Chiou \& Chen, 2007). Applying a seismic load to a virtual fixed point model encounters the following problems. First, adequate simulation of the natural period of the actual soil-pile system is difficult, because this method models piles as a frame using virtual fixed points without considering the ground. Furthermore, if the natural period of the model structure is different from that of the actual structure, the actual responses might differ greatly. Second, because the ground is not modelled, an amplified seismic wave should be used as the input spectrum; however, different codes use different input ground acceleration positions, leading to confusion in determining the appropriate input ground acceleration considering the amplification (MOF, 1999; PIANC, 2001; PARI, 2009; MLTM, 2012).

To evaluate and analyse these issues, this study reports the results of the response spectrum analysis and dynamic centrifuge tests. Input ground accelerations for the analysis were obtained at different depths based on the results of the dynamic centrifuge tests, and the response spectrum analysis with virtual fixed points was then performed using these input ground accelerations. The natural period and pile moment results of the analysis and centrifuge tests are compared. 


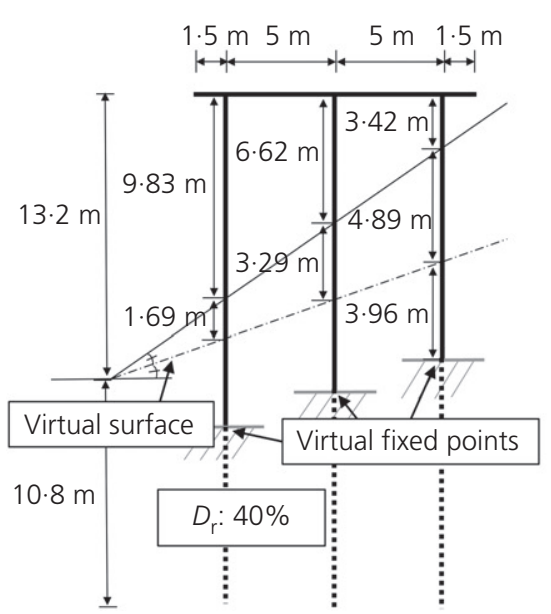

(a)

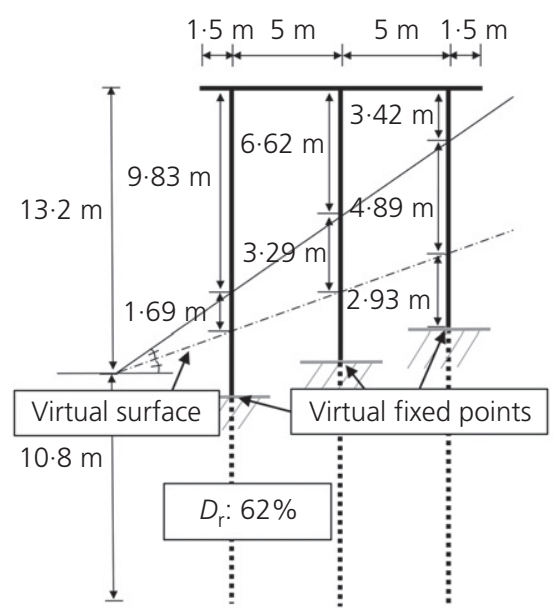

(b)

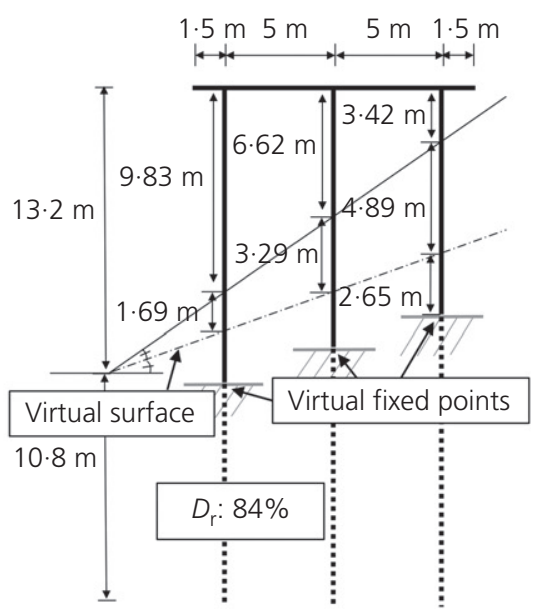

(c)

Fig. 1. Dynamic centrifuge test models and virtual fixed points for response spectrum analysis: (a) IA40 model, (b) IA62 model and (c) IA84 model

\section{CONDITIONS FOR DYNAMIC CENTRIFUGE TESTS AND RESPONSE SPECTRUM ANALYSIS}

Experiments were conducted at the Geo-Centrifuge Testing Center at KAIST, Daejeon, Korea. The geo-centrifuge testing machine has a radius of $5 \mathrm{~m}$ and can operate at a maximum of 240 g-ton (Kim et al., 2013). The model box used for the experiment was an equivalent shear beam box $0.49 \mathrm{~m}$ long, $0.49 \mathrm{~m}$ wide and $0.63 \mathrm{~m}$ high (Lee et al., 2013).

The models for the dynamic centrifuge tests were $3 \times 3$ groups of piles scaled from sections of Pohang New Port, Korea. The piles were fixed to the base plate to simulate the end bearing pile, and the ground composition was then added. The tests used a simplified ground condition comprising a sand surface sloping at $33^{\circ}$ and adjusted to different relative densities (40, 62 and 84\%; Fig. 1). Each model was at $1 / 48$ scale, and the bending stiffness of the pile was determined using equation (3) (Schofield, 1981; McCullough et al., 2007; Taylor, 2014). The model pile and deck were aluminium (A6063; $E_{\mathrm{m}}=68300 \mathrm{MPa}$; Poisson's ratio, $v=0 \cdot 3)$ (Table 1).

$$
\frac{E_{\mathrm{p}} I_{\mathrm{p}}}{E_{\mathrm{m}} I_{\mathrm{m}}}=n^{4}
$$

Table 2 lists the properties of the silica sand used as the ground soil. The average particle diameter was about $0.3 \mathrm{~mm}$, and the material was classified as poorly graded sand according to the Unified Soil Classification System (USCS). Its relative density was controlled through air pluviation, and the slope of the ground was formed using a vacuum machine. Four laser displacement meters, 17 accelerometers and 42 strain gauges were used as shown in Fig. 2.

Table 1. Properties of prototype and model (scaling factor, 48)

\begin{tabular}{l|l|c|r}
\hline & & Prototype & Model \\
\hline Pile & Diameter: $\mathrm{mm}$ & 914 & 19 \\
& Thickness: $\mathrm{mm}$ & 14 & 1 \\
& Length: $\mathrm{mm}$ & 2400 & 50 \\
& Density: $\mathrm{kN} / \mathrm{m}^{2}$ & $78 \cdot 5$ & $26 \cdot 9$ \\
\multirow{5}{*}{ Deck } & Flexural rigidity: $\mathrm{kN} \mathrm{m}{ }^{2}$ & $8 \cdot 42 \times 10^{5}$ & $0 \cdot 157$ \\
& Thickness: $\mathrm{mm}$ & 1000 & 20 \\
& Density: $\mathrm{kN} / \mathrm{m}^{2}$ & $24 \cdot 5$ & $26 \cdot 9$ \\
\hline
\end{tabular}

Table 2. Properties of the silica sand

\begin{tabular}{l|c}
\hline Soil type & Silica sand \\
\hline USCS & SP \\
$C_{\mathrm{c}}$ & $1 \cdot 16$ \\
$C_{\mathrm{u}}$ & $1 \cdot 96$ \\
$C_{\mathrm{s}}$ & $2 \cdot 63$ \\
$\gamma_{\text {dmax }}: \mathrm{kN} / \mathrm{m}^{2}$ & $16 \cdot 5$ \\
$\gamma_{\text {dmin }}: \mathrm{kN} / \mathrm{m}^{2}$ & $12 \cdot 4$ \\
\hline
\end{tabular}

The input motion was an artificial wave with 5\% damping ratio, produced as proposed by the Korean Ministry of Oceans and Fisheries (MOF, 1999) (shown in Fig. 3(a)). Figure 3(b) shows that the response spectrum curve of the artificial wave closely matched the Korean standard design response spectrum curve (MOF, 1999). The amplitude of the input acceleration was in the range of $0 \cdot 04-0.23 \mathrm{~g}$ (Table 3).

As described above, the response spectrum analysis used virtual fixed points, applied using equations (1) and (2), as shown in Fig. 1. The virtual fixed point locations were calculated using the relationship between the relative density and the $N$ value suggested by Meyerhof (1956) (Table 4). The input properties for the response spectrum analysis are the same as those used for the prototype structure (Table 1). The finite-element analysis program Midas GEN 2016 ver. 1.4 was used for the response spectrum analysis (Midas FEA, 2016).

In general, the design standards propose to model the pile as a frame structure by using virtual fixed points without considering the pile-soil interaction and then propose to conduct the response spectrum analysis for the pilesupported wharf. However, in the actual ground, seismic waves are amplified during an earthquake, and for this to be taken into account, seismic response analysis should be performed using an amplified seismic wave as the input wave.

MOF (1999) and PIANC (2001) suggested that a one-dimensional seismic response analysis be performed during the response spectrum analysis to obtain the surface acceleration. In contrast, PARI (2009) and MLTM (2012) used the seismic response acceleration obtained at the depth of the virtual fixed point $(1 / \beta)$ from a one-dimensional seismic response (Fig. 4). 


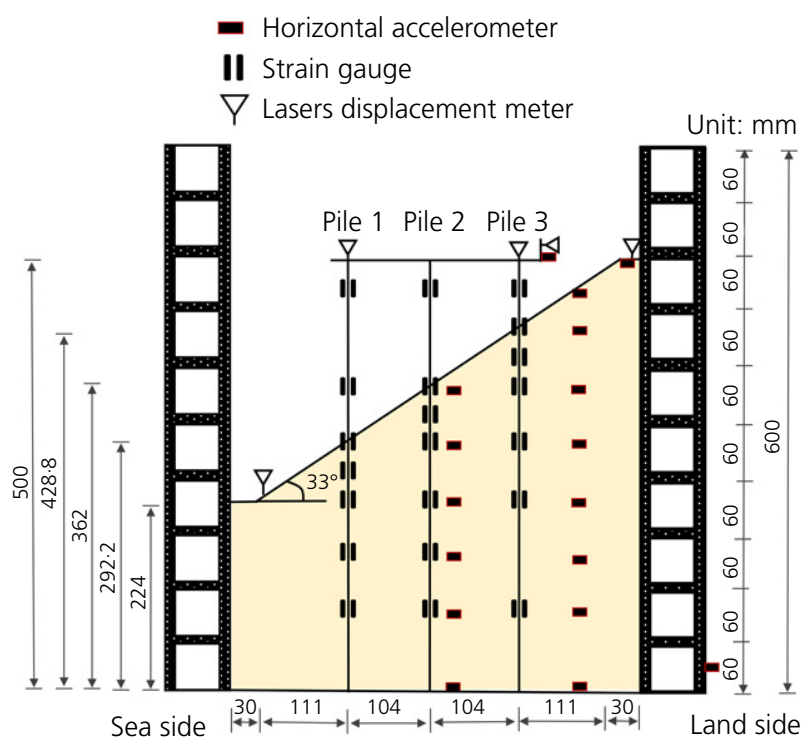

(a)

Fig. 2. Experimental model: (a) section view and (b) plan view

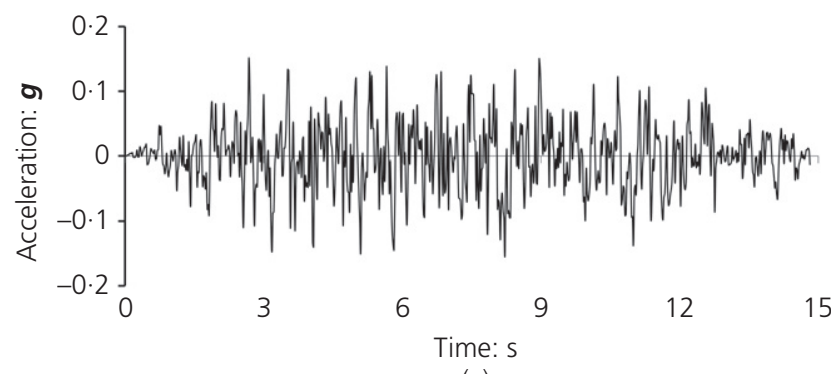

(a)

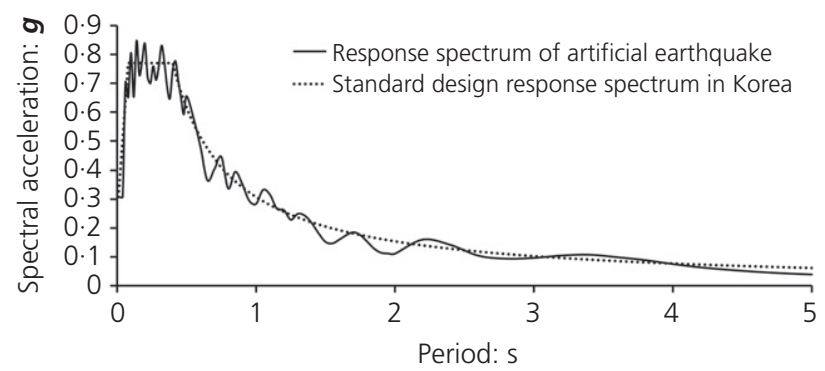

(b)

Fig. 3. Input seismic wave: (a) artificial earthquake wave and (b) comparison of response spectrum

Table 3. Experimental parameters for pile-supported wharf models

\begin{tabular}{l|c|c|c}
\hline Model & IA40 & IA62 & IA84 \\
\hline Relative density: \% & 40 & 62 & 84 \\
Input acceleration amplitude $(g)$ & $0 \cdot 04$ & $0 \cdot 05$ & $0 \cdot 09$ \\
& $0 \cdot 12$ & $0 \cdot 12$ & $0 \cdot 15$ \\
& $0 \cdot 16$ & - & - \\
& $0 \cdot 18$ & $0 \cdot 18$ & $0 \cdot 17$ \\
& $0 \cdot 23$ & $0 \cdot 21$ & $0 \cdot 23$ \\
\hline
\end{tabular}

Figure 4 also represents the peak ground acceleration (PGA) at various depths derived from the dynamic centrifuge model tests. The PGA was about $0 \cdot 12 \mathrm{~g}$ in the bedrock, $0 \cdot 151 \mathrm{~g}$ near the virtual fixed point and $0 \cdot 239 \mathrm{~g}$ in the upper

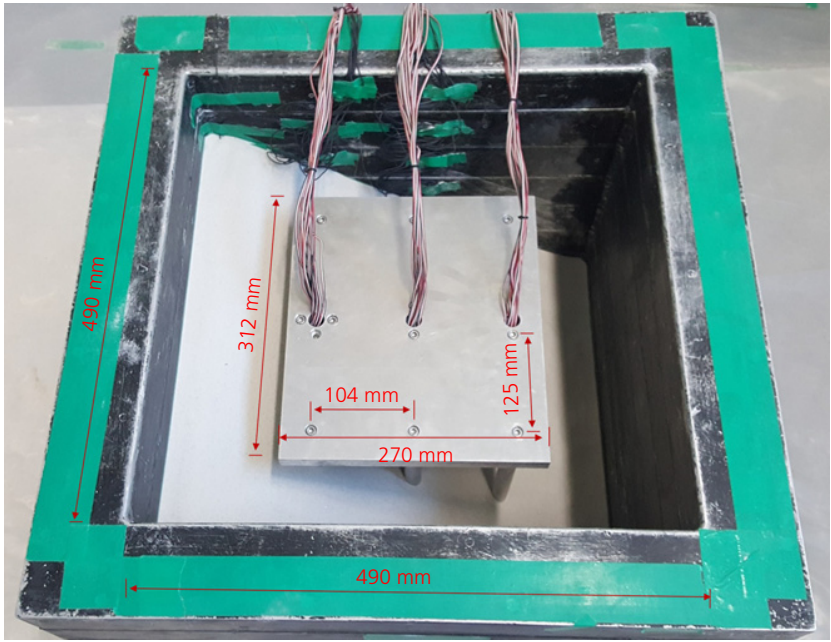

(b)

ground. The analysis used the response spectrum curves derived from the accelerations obtained during the dynamic centrifuge model tests.

\section{COMPARISON OF THE NATURAL PERIOD BETWEEN TESTS AND ANALYSIS}

The natural periods of the prototype in the dynamic centrifuge tests and the virtual fixed point model for the response spectrum analysis were compared. The natural period of the centrifuge model was calculated using the acceleration response spectral ratio, which estimates the peak value as the peak acceleration response spectrum curve divided by the base acceleration response spectrum curve (Gazetas, 1987; Laurendeau et al., 2013; Gazetas et al., 2016; Ha et al., 2017). In this study, the acceleration response spectrum of the deck (upper plate) and bedrock (base plate) were calculated to predict the natural period of the test model.

Eigenvalue analysis (Midas GEN 2016 ver. 1.4) was used to estimate the natural period when using virtual fixed points through a series of processes for solving the differential equations of a structure with multiple degrees of freedom. It can easily obtain the mode shape based on each vibration mode (Midas FEA, 2016).

Figure 5 compares the results of both methods with input accelerations of $0.21 \boldsymbol{g}$ and $0.23 \mathrm{~g}$ as examples. For the dynamic centrifuge test, the soil-pile interaction was simulated, and for the response spectrum analysis, virtual fixed points were used to simulate the frame structure without modelling the ground. The natural periods of the centrifuge tests were $0.5-0.6 \mathrm{~s}$, compared with $0.66-0.78 \mathrm{~s}$ for the response spectrum analysis. The shorter natural periods in the centrifuge tests were due to the consideration of the soil-pile interaction, the ground confining pressure and ground rigidity. The comparison of the two sets of results shows that the natural period consistently increased with decreasing relative density of ground. Furthermore, Fig. 5 shows that as the natural period increased, the spectral acceleration (i.e. the input acceleration) decreased, and thus that the response spectrum analysis underestimated the dynamic response. This trend is consistent for the response spectrum curves at the bedrock, the virtual fixed points and the ground surface. Therefore, the responses of the analysis 
Table 4. Relationship between relative density and $N$ value

\begin{tabular}{l|c|c|c|c|c}
\hline Consistency & Very loose & Loose & Medium & Dense & Very dense \\
\hline Relative density & $<0 \cdot 2$ & $0 \cdot 2-0 \cdot 4$ & $0 \cdot 4-0 \cdot 6$ & $0 \cdot 6-0 \cdot 8$ & $>0 \cdot 8$ \\
$N$ value & $<4$ & $4-10$ & $10-30$ & $30-50$ & $>50$ \\
\hline
\end{tabular}

Source: Meyerhof (1956).

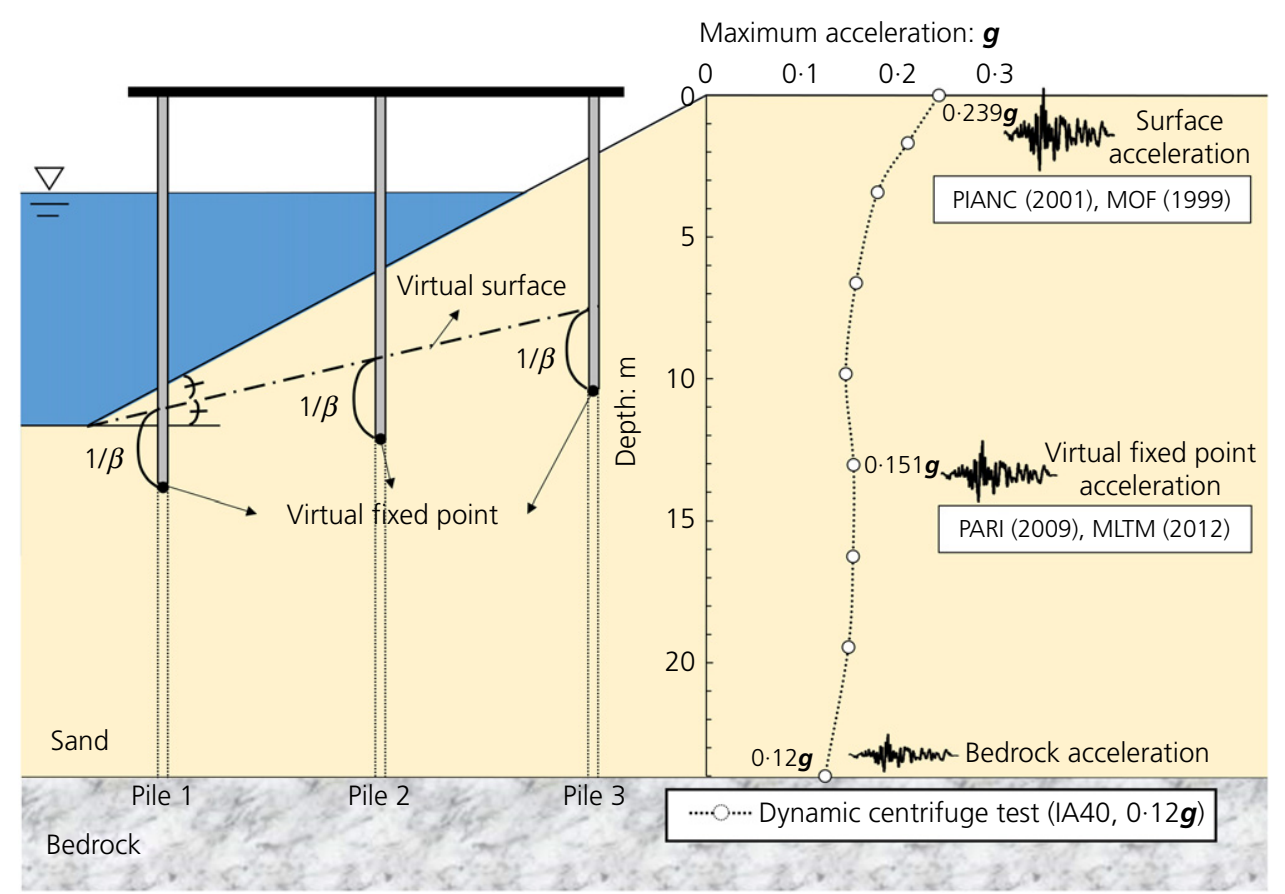

Fig. 4. Determination of input ground acceleration and amplified acceleration (IA40 model, input amplitude 0·12g)

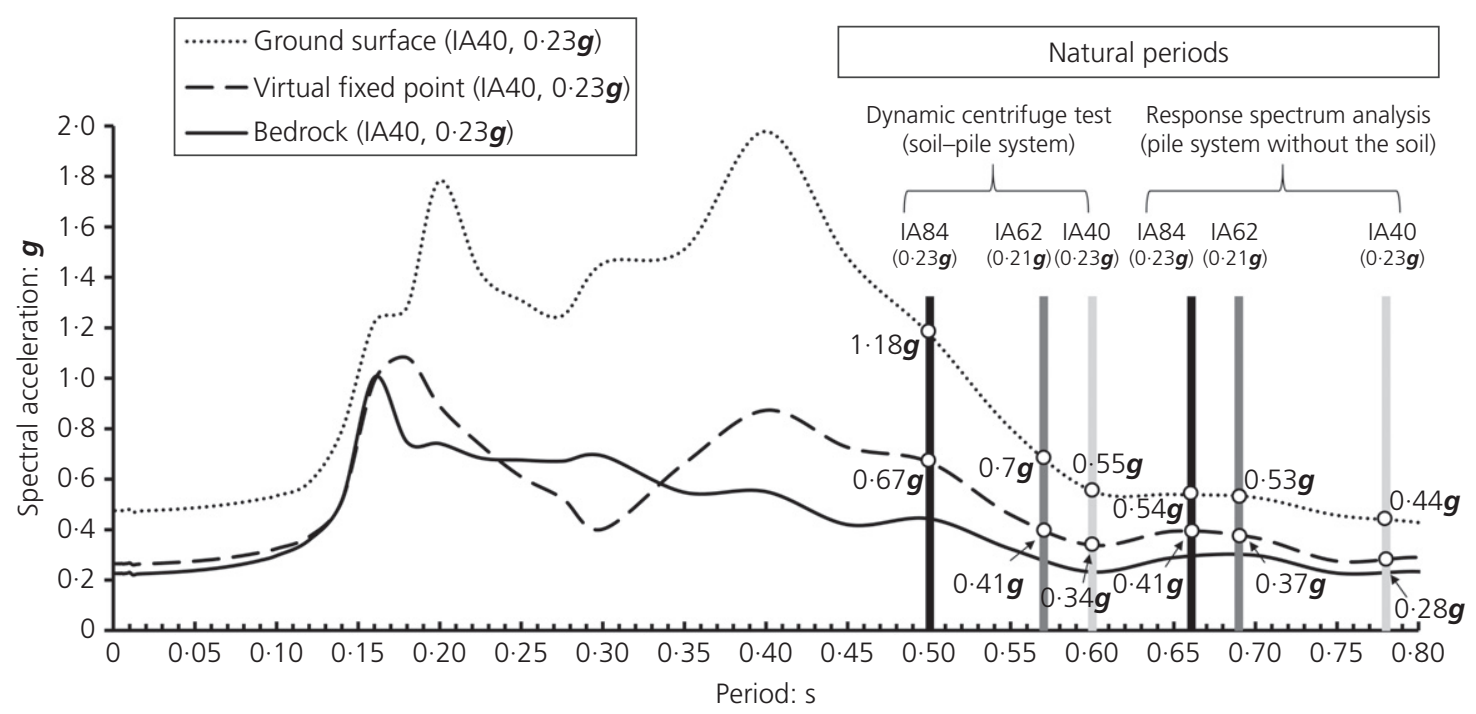

Fig. 5. Spectral accelerations with respect to depth $(\mathrm{IA} 40,0.23 \mathrm{~g})$ and the natural periods of the system in tests and analysis $(0 \cdot 21$ and $0 \cdot 23 g$ )

using virtual fixed points were smaller than those of the centrifuge tests.

\section{COMPARISON OF THE PILE MOMENT BETWEEN TESTS AND ANALYSIS}

As piles can be severely damaged by the lateral response during ground shaking, evaluation of the pile bending moment is generally important for a pile-supported wharf. Figure 6 shows the moment of pile 3 in Fig. 4 with respect to depth when the maximum moment occurred in the dynamic centrifuge tests and the response spectrum analysis at a prototype scale. The analysis applied the amplified acceleration at the virtual fixed points proposed by PARI (2009) and MLTM (2012), and at the upper ground surface proposed by MOF (1999) and PIANC (2001). In the 

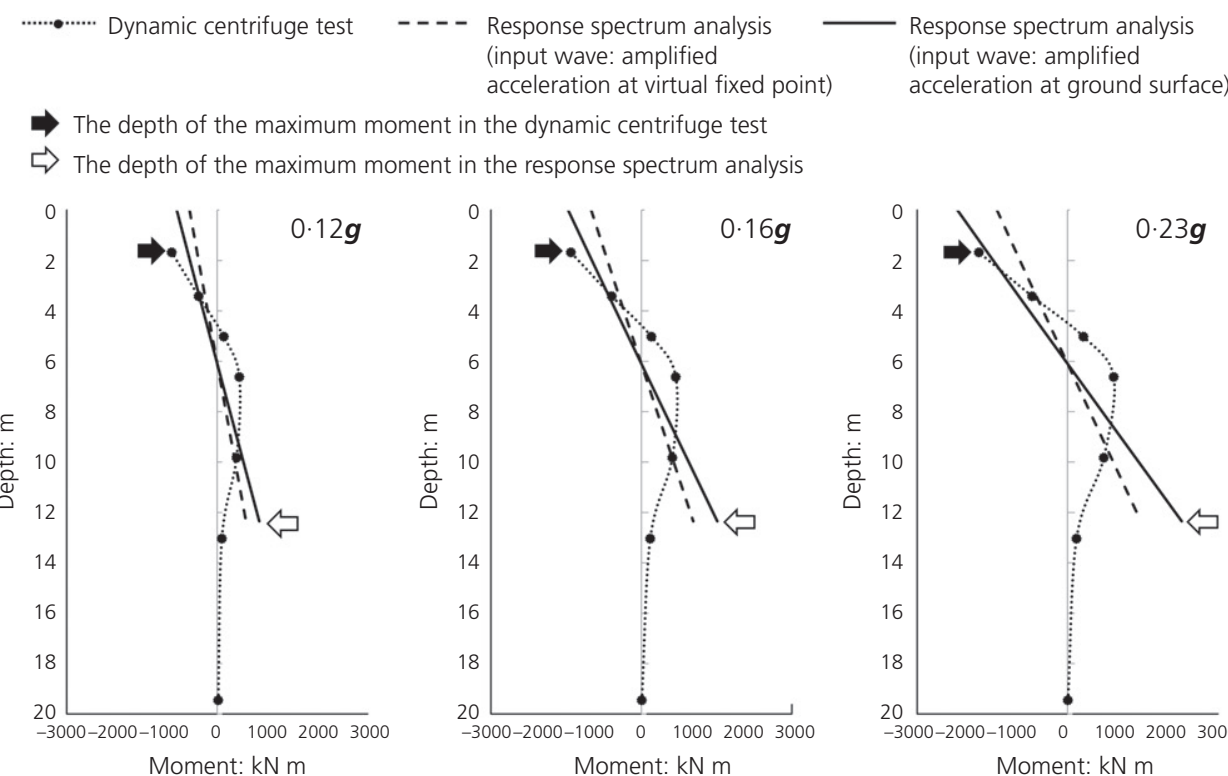

The depth of the maximum moment in the dynamic centrifuge test

moment in the response spectrum analysis

Moment: kN m
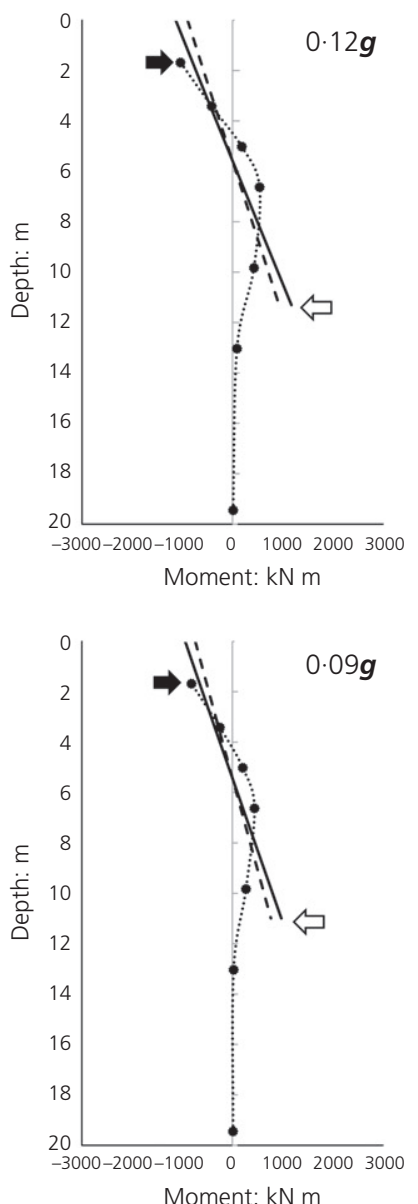

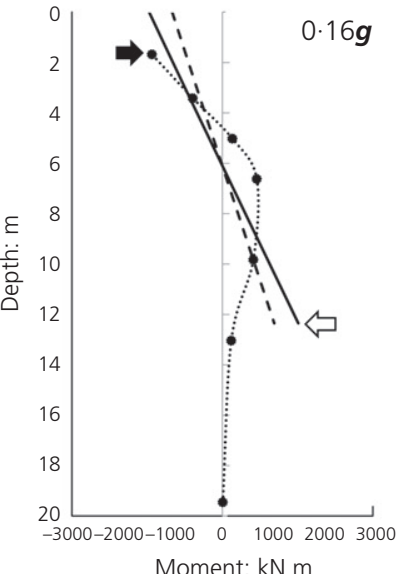

(a)

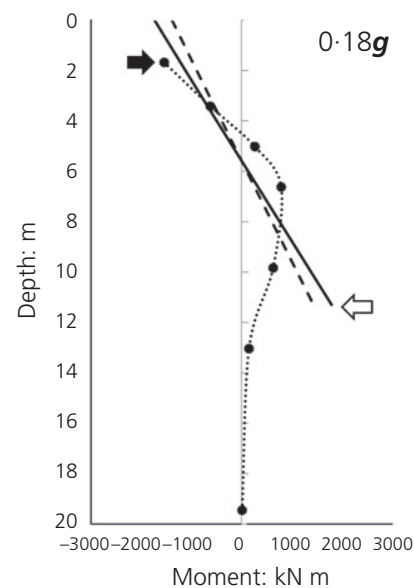

(b)

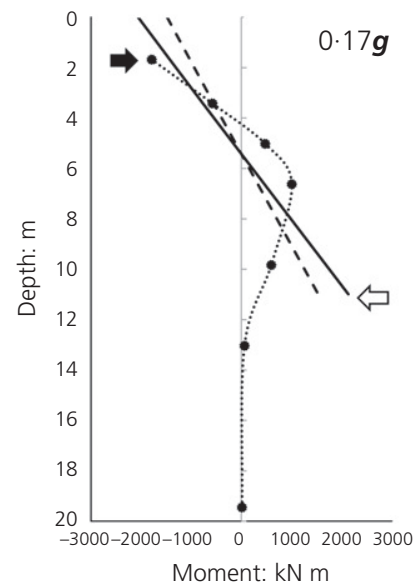

(c)
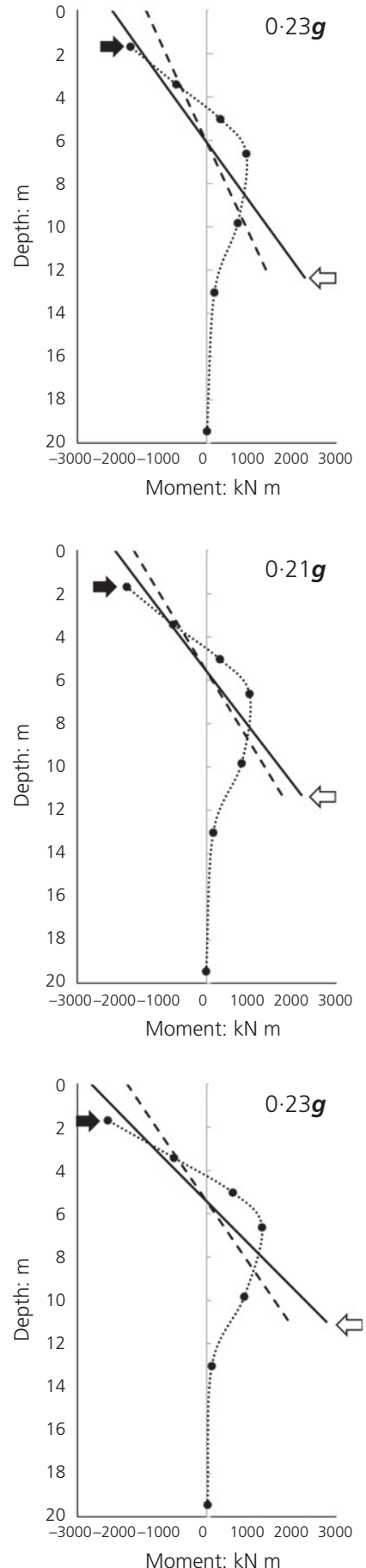

Fig. 6. Pile moments from dynamic centrifuge tests and response spectrum analysis (at prototype scale, pile 3): (a) IA40, (b) IA62 and (c) IA84

dynamic centrifuge tests, the maximum moment occurred at the top of the pile, and then decreased to zero at a depth of about $14 \mathrm{~m}$ (Fig. 6). As the intensity of the input acceleration increased, the moment result also increased. Conversely, the response spectrum analysis revealed that the maximum moment occurred at the bottom of the pile, and then changed linearly, because the analysis used virtual fixed points without considering the ground.
Figure 7 shows the pile moment with respect to depth when the maximum moment occurred in the test and analysis at a prototype scale for different piles of the IA40 model $(0 \cdot 23 \mathrm{~g})$. The test and analysis results show the position of the maximum moment. With increasing ground height, the position of the maximum moment also increased. In addition, the moment value increased from pile 1 to pile 3 due to the largest kinematic force of the ground being in pile 3 . 
The depth of the maximum moment in the dynamic centrifuge test

$\Rightarrow$ The depth of the maximum moment in the response spectrum analysis
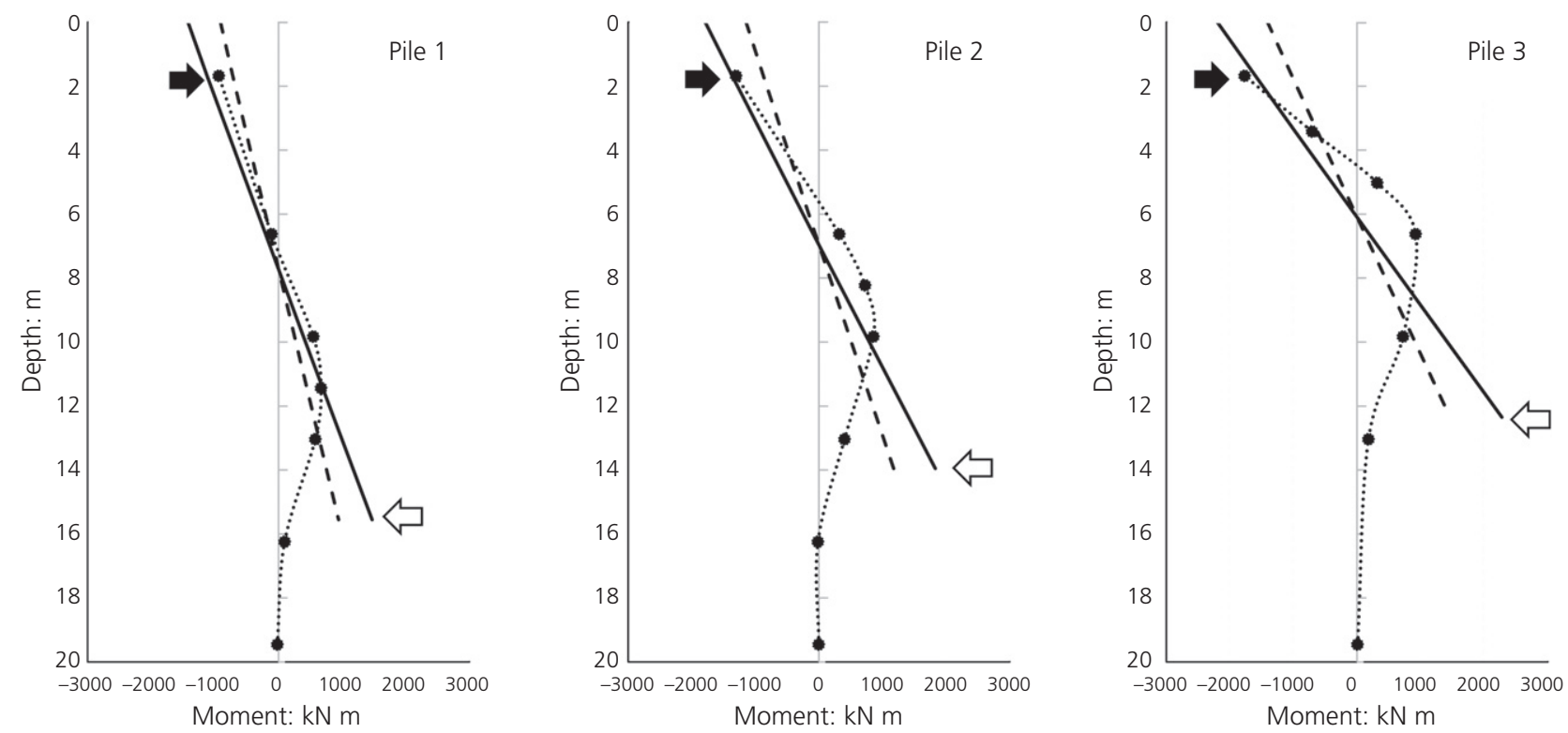

Fig. 7. Pile moments from dynamic centrifuge tests and response spectrum analysis (at prototype scale, IA40, $0 \cdot 23 \mathrm{~g}$ )

Table 5 compares the maximum pile moments obtained from the analysis and centrifuge tests. The analysis using amplified acceleration at the virtual fixed points yielded results $6-37 \%$ smaller than the centrifuge tests, because the natural period in the analysis was $0 \cdot 15-0 \cdot 2 \mathrm{~s}$ longer than that of the dynamic centrifuge tests. Consequently, spectral acceleration was reduced by $39 \%$ and the responses were underestimated (Fig. 5). In addition, the maximum pile moments of the analysis using the acceleration at the upper ground surface were $8-29 \%$ larger than those obtained by the dynamic centrifuge tests (except in three cases which were $6-8 \%$ lower), because the amplified acceleration at the ground surface was 32-57\% larger than that at the virtual fixed point inside the ground where the pile was embedded (Fig. 5). Analysis using amplified acceleration at either the virtual fixed point or the upper ground surface does not simulate the pile moment of the actual pilesupported wharf system. Overall, the response spectrum analysis using virtual fixed points appears unable to adequately simulate the pile response under the seismic load. Therefore, it is desirable to perform the analysis without using virtual fixed points and using a soil-spring model for an accurate seismic design.

\section{CONCLUSIONS}

Response spectrum analysis using virtual fixed points was compared with dynamic centrifuge model tests to evaluate

Table 5. Comparison of maximum pile moments (in prototype)

\begin{tabular}{|c|c|c|c|c|c|c|}
\hline \multirow[t]{3}{*}{ Model } & \multirow{3}{*}{$\begin{array}{l}\text { Input acceleration } \\
\text { amplitude }(\mathbf{g})\end{array}$} & \multirow{3}{*}{$\begin{array}{c}\begin{array}{c}\text { Dynamic centrifuge } \\
\text { test }\end{array} \\
\text { Moment: } \mathrm{kN} \mathrm{m}\end{array}$} & \multicolumn{4}{|c|}{ Response spectrum analysis } \\
\hline & & & \multicolumn{2}{|c|}{$\begin{array}{c}\text { Input seismic wave: amplified } \\
\text { acceleration at virtual fixed point } \\
\text { location }\end{array}$} & \multicolumn{2}{|c|}{$\begin{array}{c}\text { Input seismic wave: amplified } \\
\text { acceleration at ground surface } \\
\text { location }\end{array}$} \\
\hline & & & Moment: $\mathrm{kN} \mathrm{m}$ & Difference: $\%$ & Moment: $\mathrm{kN} \mathrm{m}$ & Difference: $\%$ \\
\hline IA40 & $\begin{array}{l}0 \cdot 04 \\
0 \cdot 12 \\
0 \cdot 16 \\
0 \cdot 18 \\
0 \cdot 23\end{array}$ & $\begin{array}{r}293 \cdot 3 \\
907 \cdot 4 \\
1404 \cdot 6 \\
1623 \cdot 0 \\
1767 \cdot 8\end{array}$ & $\begin{array}{r}211 \cdot 6 \\
572 \cdot 3 \\
1035 \cdot 5 \\
1190 \cdot 1 \\
1459 \cdot 3\end{array}$ & $\begin{array}{l}-28 \\
-37 \\
-26 \\
-27 \\
-17\end{array}$ & $\begin{array}{r}277 \cdot 0 \\
837 \cdot 4 \\
1514 \cdot 0 \\
1759 \cdot 1 \\
2274 \cdot 7\end{array}$ & $\begin{array}{r}-6 \\
-8 \\
8 \\
8 \\
29\end{array}$ \\
\hline IA62 & $\begin{array}{l}0 \cdot 06 \\
0 \cdot 12 \\
0 \cdot 18 \\
0 \cdot 21\end{array}$ & $\begin{array}{r}456 \cdot 2 \\
1036 \cdot 9 \\
1541 \cdot 4 \\
1852 \cdot 3\end{array}$ & $\begin{array}{r}349 \cdot 3 \\
928 \cdot 4 \\
1434 \cdot 1 \\
1745 \cdot 7\end{array}$ & $\begin{array}{r}-23 \\
-10 \\
-7 \\
-6\end{array}$ & $\begin{array}{r}428 \cdot 3 \\
1173 \cdot 2 \\
1795 \cdot 1 \\
2200 \cdot 3\end{array}$ & $\begin{array}{r}-6 \\
13 \\
16 \\
19\end{array}$ \\
\hline IA84 & $\begin{array}{l}0 \cdot 09 \\
0 \cdot 15 \\
0 \cdot 17 \\
0 \cdot 23\end{array}$ & $\begin{array}{r}813 \cdot 7 \\
1441 \cdot 5 \\
1819 \cdot 0 \\
2296 \cdot 5\end{array}$ & $\begin{array}{r}767 \cdot 4 \\
1342 \cdot 7 \\
1531 \cdot 9 \\
1910 \cdot 9\end{array}$ & $\begin{array}{r}-6 \\
-7 \\
-16 \\
-17\end{array}$ & $\begin{array}{r}974 \cdot 6 \\
1750 \cdot 1 \\
2132 \cdot 4 \\
2776 \cdot 4\end{array}$ & $\begin{array}{l}20 \\
21 \\
17 \\
21\end{array}$ \\
\hline
\end{tabular}


its applicability to the seismic design of pile-supported wharves. It could not adequately simulate the natural period of the wharf system including soil. In addition, analysis using amplified acceleration at the virtual fixed points proposed by PARI (2009) and MLTM (2012) yielded smaller pile moments than those measured in centrifuge tests. This result arose because the use of virtual fixed points increased the natural period and the pile moment values were underestimated due to the decrease of the spectral acceleration as the input acceleration. However, analysis using the acceleration at the ground surface proposed by PIANC (2001) and MOF (1999) generated larger moments than those observed in the centrifuge tests, because the amplified acceleration at the ground surface was larger than the amplified acceleration inside the ground. Overall, the response spectrum analysis using virtual fixed points cannot adequately simulate pile responses under seismic loads. Therefore, a soil-spring model should be employed to ensure accurate seismic design.

\section{ACKNOWLEDGEMENTS}

This research was supported by the project entitled 'Development of performance-based seismic design technologies for advancement in design codes for port structures' funded by the Ministry of Oceans and Fisheries of Korea.

\section{REFERENCES}

CEN (European Committee for Standardization) (2005). EN 1998-2: Eurocode 8: Design of structures for earthquake resistance. Part 2: Bridge. Brussels, Belgium: CEN.

Chen, Y. (1997). Assessment on pile effective lengths and their effects on design - I. Assessment. Comput. Struct. 62, No. 2, 265-286.

Chiou, J. S. \& Chen, C. H. (2007). Exact equivalent model for a laterally-loaded linear pile-soil system. Soils Found. 47, No. 6, $1053-1061$.

Gazetas, G. (1987). Seismic response of earth dams: some recent developments. Soil Dyn. Earthq. Engng 6, No. 1, 2-47.

Gazetas, G., Garini, E. \& Zafeirakos, A. (2016). Seismic analysis of tall anchored sheet-pile walls. Soil Dyn. Earthq. Engng 91, 209-221.

Ha, J. G., Park, H. J., LEE, M. G., Lee, H. L., Kim, D. S. Kwon, S. Y. \& Kim, H. U. (2017). Seismic behavior of LNG storage tank considering soil-foundation-structure interaction with different foundation types. Proceedings of the 19th international conference on soil mechanics and geotechnical engineering, pp. 931-934. Seoul, Korea: Korean Geotechnical Society.

Jiahao, L. (1992). A fast CQC algorithm of PSD matrices for random seismic responses. Comput. Struct. 44, No. 3, 683-687.

Kim, D. S., Kim, N. R., Choo, Y. W. \& Cho, G. C. (2013). A newly developed state-of-the-art geotechnical centrifuge in Korea. KSCE J. Civil Engng 17, No. 1, 77-84.
Kiureghian, A. D. (1981). A response spectrum method for random vibration analysis of MDF systems. Earthq. Engng Struct. Dyn. 9, No. 5, 419-435.

Kiureghian, A. D. \& Neuenhofer, A. (1992). Response spectrum method for multi-support seismic excitations. Earthq. Engng Struct. Dyn. 21, No. 8, 713-740.

Laurendeau, A., Cotton, F., Ktenidou, O. J., Bonilla, L. F. \& Hollender, F. (2013). Rock and stiff-soil site amplification: dependency on VS 30 and kappa ( $\kappa$ 0). Bull. Seismol. Soc. Am. 103, No. 6, 3131-3148.

Lee, S. H., Choo, Y. W. \& Kim, D. S. (2013). Performance of an equivalent shear beam (ESB) model container for dynamic geotechnical centrifuge tests. Soil Dyn. Earthq. Engng 44, 102-114.

McCullough, N. J., Dickenson, S. E., Schlechter, S. M. \& Boland, J. C. (2007). Centrifuge seismic modeling of pilesupported wharves. Geotech. Test. J. 30, No. 5, 349-359.

Meyerhof, G. G. (1956). Penetration tests and bearing capacity of cohesionless soils. J. Soil Mech. Found. Div. 82, No. 1, 1-19.

Midas, F. E. A. (2016). Analysis and algorithm manual. Gyeonggi, Korea: Midas FEA.

MLTM (Ministry of Land, Transport and Maritime Affairs) (2012). Seismic performance evaluation \& improvement revision of existing structures (harbours). Sejong, Korea: Korea Infrastructures Safety and Technology Corporation (in Korean).

MOF (Ministry of Oceans and Fisheries) (1999). Seismic design standards of harbour and port. Sejong, Korea: Ministry of Oceans and Fisheries (in Korean).

Nair, K., Gray, H. \& Donovan, N. (1969). Analysis of pile group behaviour. In Performance of deep foundations. pp. 118-159. America Society for Testing and Materials.

PARI (Port and Airport Research Institute) (2009). Technical standards and commentaries for port and harbour facilities in Japan. Tokyo, Japan: The Overseas Coastal Area Development Institute of Japan.

PIANC (International Navigation Association) (2001). Seismic design guidelines for port structures. Rotterdam, Netherlands: International Navigation Association.

Schofield, A. N. (1981). Dynamic and earthquake geotechnical centrifuge modelling. Proceedings: first international conference on recent advanced in geotechnical earthquake engineering and soil dynamics. pp. 1081-1100. St. Louis, MO, USA: Earthquake Engineering and Soil Dynamics.

Su, L., Dong, S. L. \& Kato, S. (2006). A new average response spectrum method for linear response analysis of structures to spatial earthquake ground motions. Engng Struct. 28, No. 13, $1835-1842$.

Taghavi, S. \& Miranda, E. (2010). Response spectrum method for estimation of peak floor acceleration demand. Proceeings of the 14th world conference on earthquake engineering(14WCEE), pp. 627-638. Beijing, China: International Association for Earthquake Engineering.

Taylor, R. E. (2014). Geotechnical centrifuge technology. London, UK: CRC Press.

Wilson, E. L., Der Kiureghian, A. \& Bayo, E. P. (1981). A replacement for the SRSS method in seismic analysis. Earthq. Engng Struct. Dyn. 9, No. 2, 187-192 